Illinois State University

ISU ReD: Research and eData

Theses and Dissertations

3-28-2021

\title{
Co-Localization Of D1 And Darpp-32 In Methamphetamine- Treated Rat Nucleus Accumbens, Perirhinal Cortex, And Hippocampus
}

Yonca Cam

Illinois State University, ynccam@gmail.com

Follow this and additional works at: https://ir.library.illinoisstate.edu/etd

Part of the Psychology Commons

\section{Recommended Citation}

Cam, Yonca, "Co-Localization Of D1 And Darpp-32 In Methamphetamine-Treated Rat Nucleus Accumbens, Perirhinal Cortex, And Hippocampus" (2021). Theses and Dissertations. 1357.

https://ir.library.illinoisstate.edu/etd/1357

This Thesis is brought to you for free and open access by ISU ReD: Research and eData. It has been accepted for inclusion in Theses and Dissertations by an authorized administrator of ISU ReD: Research and eData. For more information, please contact ISUReD@ilstu.edu. 


\section{CO-LOCALIZATION OF D1 AND DARPP-32 IN METHAMPHETAMINE-TREATED RAT NUCLEUS ACCUMBENS, PERIRHINAL CORTEX, AND HIPPOCAMPUS}

\section{YONCA CAM}

43 Pages

Methamphetamine abuse is a major health concern that has been associated with adverse effects such as behavioral disturbances, impaired memory, and cognitive deficits. Chronic use of methamphetamine has been found to cause persistent changes in dopamine receptors and DARPP-32 expression in the rat striatum. Because methamphetamine use has been associated with memory and cognitive impairments, chronic effects in memory-related regions should be thoroughly examined as well. The current study investigated the long-term effects of methamphetamine self-administration on D1 receptor and DARPP-32 expression on the subregions of nucleus accumbens, hippocampus, and perirhinal cortex via immunostaining. I expected to find decreased levels of D1 and DARPP-32 expression in subjects that selfadministered methamphetamine compared to saccharin. The results for D1 receptors were inconclusive due to technical difficulties. DARPP-32 expression results did not show a significant effect of methamphetamine. The findings suggest that methamphetamine did not cause any persistent effects on DARPP-32 levels. However, the experiment had some important limitations that should be taken into consideration.

KEYWORDS: immunohistochemistry, methamphetamine, dopamine D1 receptors, DARPP-32, nucleus accumbens, hippocampus, perirhinal cortex 


\title{
CO-LOCALIZATION OF D1 AND DARPP-32 IN METHAMPHETAMINE-TREATED RAT \\ NUCLEUS ACCUMBENS, PERIRHINAL CORTEX, AND HIPPOCAMPUS
}

\author{
YONCA CAM
}

\author{
A Thesis Submitted in Partial \\ Fulfillment of the Requirements \\ for the Degree of \\ MASTER OF SCIENCE \\ Department of Psychology \\ ILLINOIS STATE UNIVERSITY
}

2021 
(C) 2021 Yonca Cam 
CO-LOCALIZATION OF D1 AND DARPP-32 IN METHAMPHETAMINE-TREATED RAT

NUCLEUS ACCUMBENS, PERIRHINAL CORTEX, AND HIPPOCAMPUS

YONCA CAM

COMMITTEE MEMBERS:

Byron A. Heidenreich, Chair

Scott J. Jordan 


\section{ACKNOWLEDGMENTS}

First, I would like to express my gratitude to Dr. Joshua Gulley of the University of Illinois and his lab for providing me with the subjects used in this thesis project. I would like to extend my sincere appreciation to my committee chair, Dr. Byron Heidenreich, and committee member, Dr. Scott Jordan, for their continuous guidance and support. Without your incredible understanding and support, this project would not be attainable. I would also like to thank all the faculty members and my friends for making my time at Illinois State University a great experience. Lastly, I am extremely grateful to my family for supporting my academic career and encouraging my decisions. 


\section{CONTENTS}

Page

ACKNOWLEDGMENTS

TABLES

FIGURES

LIST OF ABBREVIATIONS vi vi

CHAPTER I: INTRODUCTION 1

History of Methamphetamine Use $\quad 1$

Prevalence Rates of Methamphetamine Use 1

Physiological Effects of Methamphetamine 2

$\begin{array}{ll}\text { Dopaminergic Pathways } & 3\end{array}$

Dopamine Receptors $\quad 5$

$\begin{array}{ll}\text { Phosphorylation of DARPP-32 } & 6\end{array}$

$\begin{array}{ll}\text { Regions of Interest } & 8\end{array}$

$\begin{array}{ll}\text { Nucleus Accumbens } & 8\end{array}$

Hippocampus and Perirhinal Cortex 9

$\begin{array}{ll}\text { The Present Study } & 10\end{array}$

Research Questions 11

CHAPTER II: METHODOLOGY 12

Subjects and Methamphetamine Treatment $\quad 12$

$\begin{array}{ll}\text { Antibodies } & 13\end{array}$

$\begin{array}{ll}\text { Immunohistochemistry } & 14\end{array}$

$\begin{array}{ll}\text { Statistical Analyses } & 16\end{array}$ 
$\begin{array}{ll}\text { CHAPTER III: RESULTS } & 18\end{array}$

$\begin{array}{ll}\text { Dopamine D1 Histology } & 18\end{array}$

$\begin{array}{ll}\text { DARPP-32 Histology } & 18\end{array}$

$\begin{array}{ll}\text { Nucleus Accumbens } & 18\end{array}$

$\begin{array}{ll}\text { Perirhinal Cortex } & 20\end{array}$

$\begin{array}{ll}\text { Hippocampus } & 21\end{array}$

CHAPTER IV: DISCUSSION 23

$\begin{array}{ll}\text { REFERENCES } & 27\end{array}$

APPENDIX A: DARPP-32 ANTIBODY STAINING ON NUCLEUS ACCUMBENS 39

APPENDIX B: DARPP-32 ANTIBODY STAINING ON PERIRHINAL CORTEX 40

APPENDIX C: DARPP-32 ANTIBODY STAINING ON HIPPOCAMPUS 41 


\section{TABLES}

Table

Page

1. Number of Subjects in Each Condition

13

2. Mean Specific Luminance Values for METH and Saccharin Groups in Each Subregion 


\section{FIGURES}

Figure $\quad$ Page

$\begin{array}{ll}\text { 1. Cresyl Violet Staining } & 17\end{array}$

2. D1 Staining in NAcc 18

3. DARPP-32 Staining in the NAcc 19

4. DARPP-32 Staining in the PRh 21

5. DARPP-32 Staining in the HPC 22 


\section{LIST OF ABBREVIATIONS}

AMPH, Amphetamine

DA, Dopamine

DAT, Dopamine Transporter

DARPP-32, Dopamine and cAMP-regulated phosphoprotein $($ molecular weight $=32 \mathrm{kD})$

DG, Dentate Gyrus

HPC, Hippocampus

I.P., Intraperitoneal

METH, Methamphetamine

NAc, Nucleus Accumbens

NAcc, Nucleus Accumbens Core

PB, Phosphate Buffer

PBS, Phosphate-Buffered Saline

PFC, Prefrontal Cortex

PRh, Perirhinal Cortex

SACC, Saccharin

VTA, Ventral Tegmental 


\section{CHAPTER I: INTRODUCTION}

\section{History of Methamphetamine Use}

Amphetamine (AMPH), a sympathetic nervous system stimulant, was synthesized in 1887 by a German chemist; however, it was not studied comprehensively until the 1930 s. Because AMPH provides relief by reducing nasal decongestion, it was used for the treatment of asthma in 1932. By the 1940s, AMPH was already being used in treating many conditions including narcolepsy, hyperactivity, tobacco addiction, low blood pressure, schizophrenia, morphine addiction, and many others. Methamphetamine (METH), an AMPH derivative, was synthesized in 1893 by a Japanese pharmacologist. However, METH was not commonly used until World War II when the drug was made available to the armed forces to enhance performance and alertness by the United States, Germany, and Japan. In the U.S., AMPH was available as an over-the-counter medication until the 1950s and was still widely prescribed for depression and obesity in the 1960s. The first illicit METH laboratories emerged in 1962 in San Francisco. After the use of METH increased significantly in the mid-1990s, when it was illegally produced on a massive scale by underground labs on the West Coast (for an extensive review, see Anglin et al., 2000), it became a major public health concern (Wermuth, 2000). Although METH has been legally available as a pharmaceutical tablet called Desoxyn since the 1940s to treat Attention-Deficit/Hyperactivity Disorder, narcolepsy, and obesity, it is primarily sold illegally for its recreational use (Scott et al., 2007).

\section{Prevalence Rates of Methamphetamine Use}

METH abuse has been described as an "epidemic" in the U.S. as the prevalence rates significantly increased through the early 1990s (McCaffrey, 1995). Between 2015 and 2018, 1.6 million adults reported past-year METH use in the U.S, and approximately half of these 
individuals had METH use disorder (Jones et al., 2020). Among adolescents, prevalence rates show that compared to other illicit drugs, METH use is relatively low. A national survey called Monitoring the Future reported that the annual prevalence rates in 2018 were $0.4 \%$ for $8^{\text {th }}$ graders, $0.4 \%$ for $10^{\text {th }}$ graders, and $0.5 \%$ for $12^{\text {th }}$ graders. These rates were reported to be the lowest recordings since the first measurements were taken in 1999, which suggests an overall decrease in METH use among adolescents (Lloyd et al., 2019). On the other hand, emergency room visits associated with METH have increased from 11,002 in 1996 to 102,961 in 2011 (SAMHSA, 2014). In addition, Gonzales et al. (2018) reported that the percentage of adolescents who were admitted to Los Angeles County drug treatment centers with METH being their main drug of abuse increased from $8 \%$ in 2002 to $31 \%$ in 2005 . More importantly, it has been found that METH-using youth reported greater psychosocial dysfunction and were less likely to stay drug-free throughout treatment compared to the non-METH-using youth (Rawson, 2005). Although METH use has been widely studied in adults, we know relatively little about its acute and chronic effects on the adolescent brain (Buck \& Siegel, 2015). Considering the highly addictive nature of METH and the potential brain alterations that it can cause to the developing adolescent brain (Spear, 2000), it is important to understand the chronic neurotoxic effects of METH use both in adulthood and adolescence.

\section{Physiological Effects of Methamphetamine}

METH is a central nervous system psychostimulant that can be smoked, injected, or taken orally (Gonzales et al., 2010). Acute effects of METH on the autonomic nervous system include hypertension, tachycardia, hyperthermia, and increased breathing (Scott et al., 2007). The desired cognitive effects of METH include increased energy, alertness, positive mood state, decreased appetite, and elevated self-esteem (Rawson et al., 2002). These effects are produced 
through heightened dopamine (DA), serotonin, and norepinephrine activity in the brain (Anglin et al., 2000). METH achieves this increased activity by stimulating the release of freshly synthesized catecholamines while also blocking their reuptake. Because of its similarity in structure, METH enters the presynaptic neurons through the DA, noradrenaline, and serotonin transporters and reverses their endogenous function, which redeploys monoamines from storage vesicles into the cytosol and releases them into the synapse. The released monoamines stimulate the postsynaptic receptors in the major dopaminergic, noradrenergic, and serotonergic pathways. Dopaminergic regions have been associated with the euphoric effects of the drugs.

Noradrenergic regions have various functions such as arousal, memory consolidation, and cognitive processing. Lastly, serotonergic regions are involved in respiration, pain perception, and higher-order cognitive processing (for an extensive review, see Courtney \& Ray, 2014).

\section{Dopaminergic Pathways}

The midbrain DA neurons are associated with behaviors that are involved in reward, cognition, and motor movements (Haber, 2014). Some dopaminergic neurons originate in the midbrain ventral tegmental area (VTA), which plays a central role in the processing of rewarding stimuli and drug addiction (Lupica et al., 2004), and their axons extend to several parts of the brain through several dopaminergic pathways. The vast majority of the DA in the human brain is transported through four pathways including mesolimbic, mesocortical, nigrostriatal, and tuberoinfundibular pathways. The mesocortical pathway includes DA neurons that project from VTA to the prefrontal cortex (PFC). The mesolimbic pathway, also known as the reward pathway, projects to nucleus accumbens (NAc), amygdala, and hippocampus (HPC), (for review, see Stott \& Ang, 2013). The mesocorticolimbic system (VTA, NAc, and PFC) represents a mutual substrate that plays a role in the reinforcing properties of drugs (Koob, 1992) and the 
development of behavioral sensitization (Blum et al., 2012). Behavioral sensitization is a phenomenon characterized as a progressive increase in locomotor activity and/or stereotyped responses to a stimulus (Robinson and Becker, 1986). The early action of AMPH and METH in the VTA is thought to be a critical event for the initiation of behavioral sensitization. Unlike the other major dopamine pathways in the mesocorticolimbic areas, the nigrostriatal pathway originates in the substantia nigra and projects DA to the caudate nuclei and putamen of the striatum (Haber, 2014). Lastly, the tuberoinfundibular pathway transmits DA from the hypothalamus to the pituitary gland, in which DA functions more like a hormone that inhibits the release of prolactin rather than a neurotransmitter (Scott \& Ang, 2013).

Drugs alter activity in the DA pathways in numerous ways by altering neurotransmission, which is a complicated process that involves the synthesis and storage of neurotransmitters, their release in the synapse followed by binding with pre-and post-synaptic receptors (Giros et al., 1996). Some drugs such as heroin, morphine, and other opioids increase DA activity by binding to opioid receptors located on the GABAergic axon terminals. This binding inhibits GABA release onto DA neurons which leads to enhanced DA activity (Johnson \& North, 1992). Other drugs, such as cocaine and AMPH, elevate DA levels in the NAc by directly increasing DA in the synapse and the time DA remains at the postsynaptic site. Cocaine achieves this action by blocking the presynaptic dopamine transporters, while AMPH works through increasing DA release from the synaptic vesicles (Ritz et al., 1987; Bunney \& Aghajanian, 1978). As described earlier, METH increases the amount of DA at the synapse by both stimulating the release of DA and by partially blocking the reuptake of DA by presynaptic receptors. Methamphetamineinduced neurotoxicity is evident in all dopaminergic pathways with the most notable one being in the nigrostriatal pathway (Cass, 1997). 


\section{Dopamine Receptors}

Neurotoxic effects of METH are thought to result from excess DA release and the dysregulation of DA control (for review, see Ares-Santos et al., 2013). Although METH influences DA levels through multiple mechanisms, the dopamine transporter (DAT) may be the primary location of the action. In a study by Giros et al. (1996), DAT knockout mice did not show any locomotor activity or dopamine release and reuptake after receiving either cocaine or AMPH, which suggests that DAT might be a major site for AMPH derivatives' action mechanisms. Acute administration of METH has been found to cause a rapid decrease in DAT; though, this decrease was reversible in less than 24 hours (Brown et al., 2002; Fleckenstein et al., 1997). Similar to DAT knockout mice, pretreatments with DA uptake blockers (Stephans \& Yamamoto, 1994) and DA receptor antagonists (Patrick et al., 2011) were found to attenuate METH-induced DA efflux and DAT loss.

Dopamine transmission in the brain relies on the activation of G-protein-coupled DA receptors. DA D1 receptors, one of the five DA receptor subtypes, are widely found in the brain with the highest levels found in the NAc and caudate putamen, which is comparable in both human and rat brains (for review, see Cadet et al., 2010). METH-induced neurotoxicity as a result of increased DA is thought to be a result of DA D1/D2 receptors. A study by O'Dell et al. (1993) found that pretreatment with both DA D1 and D2 receptor antagonists was effective in preventing METH-induced striatal tissue damage and DA overflow. In addition, D1 receptor knock-out mice showed decreased DA tissue damage, dopaminergic neuron loss in substantia nigra, hyperthermia, and neurotoxicity after repeated injections of METH (Ares-Santos et al., 2012). 
Several subcutaneous administrations of METH $(15 \mathrm{mg} / \mathrm{kg})$ have been shown to reduce D1 and D2 receptor sites in several brain regions with the highest impact seen in substantia nigra, followed by caudate-putamen, NAc, claustrum, entorhinal cortex, and amygdaloid area (McCabe et al., 1987). A previous study on chronic effects of AMPH (3 mg/kg), administered intraperitoneally (i.p.), during adolescence and adulthood showed a persistent D1 receptor reduction in the medial PFC (Kang et al., 2016a). For adolescent subjects, this reduction was associated with an increase in approach behavior, anhedonia, and depression- and anxiety-related behaviors in adulthood (Kang et al., 2016b). However, a similar reduction was not observed in NAc (Kang et al., 2016a).

\section{Phosphorylation of DARPP-32}

Dopamine and cAMP-regulated phosphoprotein (molecular weight $=32 \mathrm{kD})$, DARPP-32, was discovered during dopamine signaling studies (Walaas et al., 1983) and has been extensively studied to understand its mechanism of action. DARPP-32 is present in large amounts in medium-sized spiny neurons in the striatum (Ouimet et al., 1984) and is co-localized with DA D1/D2 receptors (Langley et al., 1997; Rajput et al., 2009).

DARPP-32 is essential to dopaminergic activity and efficacy (Fienberg et al., 1998). The activation of D1 receptors by DA activates adenylate cyclase and increases cAMP levels which trigger the initiation of protein kinase A (PKA) eventually leading to stimulating the phosphorylation of DARPP-32 at threonine-34 (Thr-34). Phosphorylation of DARPP-32 at Thr34 alters its biological properties, turning DARPP-32 into a potent inhibitor of protein phosphatase 1 (PP-1), which controls the activity of multiple significant substrates such as ion channels, pumps, and transcription components (Greengard, 2001). Thus, investigating DARPP32, because of its ability to modulate the PKA and PP-1 activity, is essential to understand the 
mechanism of action of DA, its interaction with other neurotransmitters, the behavioral responses to drugs of abuse and other stimuli (Greengard, 2001; Svenningsson et al., 2004) as well as PFC function (Yger \& Girault, 2011).

DARPP-32 may also be required for the actions of drugs of abuse. For instance, a study by Zachariou et al. (2006) found that DARPP-32 knockout mice do not display the typical behavioral effects of cocaine such as increased locomotor activity, indicating that phosphorylation of DARPP-32 may be required for the cocaine's mode of action. Similar results were found for morphine's effects as well. Borgkvist et al. (2007) observed that DARPP-32 knockout mice did not show an increased motor behavior after an acute morphine injection. However, DARPP-32 might not be required for rewarding properties of morphine as there were no differences between DARPP-32 knockout mice and controls in conditioned place preference (Borgkvist et al., 2007), which is a classical conditioning paradigm designed to measure "druginduced motivational state" (Scofield et al., 2016, p. 821).

Several studies on drugs of abuse found that DARPP-32 plays an important role in mediating and regulating short- and potentially long-term effects of drug use (for review, see Nairn et al., 2004). For instance, acute treatment of cocaine has been found to increase the phosphorylation of Thr-34 of DARPP-32 in the striatum (Nishi et al., 2000) and chronic treatment is associated with decreased phosphorylation of Thr-34 (Bibb et al., 2001). Chien et al. (2012) found that an acute treatment of METH (1 mg/kg, i.p.) increased DARPP-32 phosphorylation at Thr-34 and Thr-75 after an hour of injection. However, this increase in DARPP-32 phosphorylation and METH-induced increased locomotor activity was attenuated by naloxonazine, an opioid agonist, when injected prior to METH administration (Chien et al., 2012). Chronic administration of METH (4 mg/kg, intracranial) over 14 days followed by a one- 
week withdrawal showed a decreased basal phosphorylation of DARPP-32 at Thr-34 and increased basal phosphorylation at Thr-75 (Chen \& Chen, 2005).

\section{Regions of Interest}

\section{Nucleus Accumbens}

The nucleus accumbens has been considered as a major part of reward processing, motivational behavior, locomotion, learning, and other biological drives necessary for survival. The NAc can be divided into two sections: a central core and a surrounding shell. (for review, see Salgadi \& Kaplitt, 2015). Deutch and Cameron (1992) suggested that the nucleus accumbens core (NAcc) might be more aligned with the striatum while the NAc shell is connected with the mesolimbic pathway. Furthermore, other studies support that projections to the substantia nigra rise from NAcc (Berendse et al, 1992), and VTA mainly innervates NAc shell (Gerfen et al., 1987, as cited in Salgadi \& Kaplitt, 2015). These findings suggest that while NAc shell might be more associated with immediate reward processing, NAcc might be more involved in learning and behavioral responses to rewarding properties. As discussed previously, drugs of abuse increase DA influx in NAc and HPC through the mesolimbic pathway. Kleven et al., (1990) found a decrease in D1 binding sites in NAc and striatum after a 2-week long cocaine treatment (10 or $20 \mathrm{mg} / \mathrm{kg}$ ) followed by either an immediate observation or after a 2-week withdrawal period. Kang et al. (2016a) did not find any effect of chronic AMPH exposure (3mg/kg) on D1 expression in NAc, but there was a significant reduction in medial PFC. These differences could be dose-dependent considering that NAc is less sensitive to DA-depleting changes (Cass, 1997). As discussed earlier, drug effects on DARPP-32 in the striatum, which includes NAc, have been examined thoroughly, with most findings suggesting an acute increase in DARPP-32 phosphorylation and basal decrease after chronic drug exposures. Although drug-induced 
changes in DARPP-32 expression in NAcc and shell has not been investigated separately, it is known that persistent changes in drug-induced protein expression in the NAc occur in the core rather than the shell (Miller \& Marshall, 2005). This could be a result of different mechanisms of reward processing associated with each section. Also, because DARPP-32 signaling has been associated with psychomotor stimulation (Borgkvist et al., 2007), and NAcc is more associated with motor and behavioral responses to rewarding stimuli, the current experiment will focus on the DARPP-32 expression in NAcc.

\section{Hippocampus and Perirhinal Cortex}

Drugs of abuse are associated with disturbed learning as well as the development of maladaptive memories between environmental cues and drug effects, which might play a role in future drug use. Although acute effects of AMPHs include increased memory consolidation, recall, and attention, chronic use is associated with impaired learning, memory, attention, and decision making (for review, see Kutlu \& Gould, 2016). These hippocampal effects might be a result of DA activity. Because DA antagonists can block AMPH-induced conditioned place preference (e.g., Bardo et al., 1999), it is possible that enhanced DA activity might be a cause of hippocampal-learning impairments. It has been suggested that compared to other DA receptors, DA D1 and D2 receptors may have a greater effect on hippocampal learning (for review, see Berke \& Hyman, 2000). DA receptors are most highly expressed in the dentate gyrus (DG), CA1, and CA3 subregions of the HPC (Yokoyoma et al., 1995).

Both acute and repeated administrations of METH have been found to disrupt object recognition memory in rats (Reichel et al., 2011; Schroder et al., 2003). Although both HPC and perirhinal cortex (PRh) have been found to be associated with recognition memory, research has shown that $\mathrm{PRh}$ is more concerned with differentiating familiarity, while HPC is concerned with 
judging the likelihood of previous exposure (for review, see Brown \& Aggleton, 2001). PRh, which has high D1 and D2 DA receptor expression through all its layers, receives input from CA1 and the subiculum of the HPC. This input has been shown to arrive at layers V and VI of the perirhinal cortex (for review, see Kealy \& Commins, 2011).

\section{The Present Study}

The purpose of the current experiment was to examine the long-term and persistent effects of chronic METH self-administration on DA D1 and DARPP-32 levels in NAcc, HPC, and PRh. The actions of METH seem to cause many short- and long-term alterations in the mesolimbic system through influencing DA influx, DAT levels (Giros et al., 1996), DA receptors (McCabe et al., 1987), and eventually DARPP-32 phosphorylation (Chen \& Chen, 2005). Because most previous research has focused on the striatum, the effects on HPC and PRh have not been thoroughly examined. However, previous research showed that METH has an ability to disrupt recognition memory (e.g., Reichel et al., 2011), which might be associated with some changes in recognition memory-related regions such as HPC and PRh.

Considering all the previous findings in the field, the chronic and persistent effects of METH should be examined thoroughly because the long-term effects in the mesocorticolimbic system could potentially encourage future drug use and behavioral disturbances (e.g., Kang et al., 2016a). This could especially be true for adolescents as their brains are going through a series of changes in many regions (for review, see Brenhouse \& Andersen, 2011). Because DA D1 receptors and DARPP-32 in NAcc, HPC, and PRh might have significant roles in reward processing, drug addiction, as well as memory impairment, the proposed study investigated the long-term alterations in D1 receptors and DARPP-32 expression in rats that were exposed to chronic self-administration of METH or saccharin to answer the following research questions. 


\section{Research Questions}

Research Question 1: How does chronic administration of METH affect the density of dopamine D1 receptors in the NAc, CA, and PRh? I predicted that chronic METH selfadministration would decrease the density of dopamine D1 receptors in NAc, CA, and PRh.

Research Question 2: How does chronic administration of METH affect the density of DARPP-32 expression in the NAc, CA, and PRh? I predicted that chronic METH selfadministration would decrease the density of DARPP-32 in NAc, CA, and PRh. 


\section{CHAPTER II: METHODOLOGY}

\section{Subjects and Methamphetamine Treatment}

Brain tissues were obtained from the laboratory of Dr. Joshua Gulley at University of Illinois, Urbana-Champaign. The subjects were 3 male and 11 female $(\mathrm{METH}=7$, saccharin $=7)$ Sprague-Dawley rats. Animals were housed on a reversed 12-hr light/dark cycle at their facility with food and water available ad libitum. All training and testing were completed during the rats' dark cycle. The experimental procedures were approved by the Institutional Animal Care and Use Committee at the University of Illinois at Urbana-Champaign and were consistent with the Guide for the Care and Use of Laboratory Animals (National Research Council, 2011). As described in Westbrook et al. (2020), the experiment included two groups: adolescent-onset and adult-onset METH exposure. Intravenous catheterization surgery was performed approximately on P32 or P82, which was followed by a 5-day recovery and daily self-administration sessions of METH and saccharin. Self-administration, which lasted from P41 to P62 or P91 to P112, was stable across groups. During the short-access period, the first 7-days, the administration was between 2-3 mg/kg per day. During the long-access days, remaining 14-days, it was approximately between 8 and $10 \mathrm{mg} / \mathrm{kg}$ each day. After 19 days of abstinence and cognitive tests, which included a novel object recognition task and object-in-place task, the animals were anesthetized with $195 \mathrm{mg} / \mathrm{kg}$ pentobarbital and perfused transcardially with ice-cold saline. The brains were removed, placed in chilled saline for $1 \mathrm{~min}$, and dissected using a chilled metal brain matrix. Tissues were stored at $-80^{\circ} \mathrm{C}$ until they were treated with $4 \%$ p-formaldehyde in $0.1 \mathrm{M}$ phosphate buffer (PB) for $24 \mathrm{~h}$ and then stored in $20 \%$ sucrose for at least 3 days prior to sectioning. 
In this experiment, I used 6 tissues $(\mathrm{METH}=3$, saccharin = 3) each for NAcc, HPC and PRh staining. However, one of the subjects in the METH condition was excluded later due to unsuccessful staining. Another METH subject in PRh was excluded because of an error in sectioning. The final number of subjects for each region in the METH and saccharin groups are listed in Table 1 with their age-of-onset of exposure.

\section{Table 1}

Number of Subjects in Each Condition

\begin{tabular}{|c|c|c|c|c|}
\hline & \multicolumn{2}{|c|}{ METH } & \multicolumn{2}{|c|}{ Saccharin } \\
\hline & Adult-Onset & Adolescent-Onset & Adult-Onset & Adolescent-Onset \\
\hline NAc & 2 & 1 & 0 & 2 \\
\hline $\mathrm{PRh}$ & 1 & 1 & 1 & 2 \\
\hline HPC & 2 & 1 & 1 & 2 \\
\hline
\end{tabular}

\section{Antibodies}

The first D1DR antibodies used in initial D1 staining were selected from Stojanovic et al. (2015). The primary antibody, monoclonal anti-D1 dopamine receptor antibody (\#D2944) was purchased from Sigma Aldrich (St. Louis, MO, USA). The AffiniPure Fab Fragment Goat AntiRat IgG (H+L) (\#112-006-143) and the secondary antibody, peroxidase-conjugated AffiniPure Donkey Anti-Goat IgG (H+L) (\#705-035-147) were purchased from Jackson Immuno Research (West Grove, PA, USA). For the second D1 staining, DRD1 Polyclonal antibody (17934-1-AP) was obtained from Proteintech (Rosemont, IL, USA). DARPP-32 staining was completed using 
the protocol by Smith et al. (2015), using a DARPP-32 primary antibody, rabbit anti-DARPP-32 (Abcam \#40801) and a Vector Elite ABC kit by Vector Laboratories (Burlingame, CA, USA).

\section{Immunohistochemistry}

Brain tissues were sectioned either coronally or horizontally at a thickness of $40-\mu \mathrm{m}$ using a cryostat microtome. Every third section for each tissue was assigned to either primary antibody, omit primary antibody, or cresyl violet-staining groups. Cresyl violet-stained sections were used to examine the gross structure of the tissue and determine structure boundaries. Omit primary antibody control sections, omits, went through the same immunostaining protocols as the primary antibody sections except that they were incubated without the primary antibody to control for non-specific tissue staining from the procedures. Sections were immediately mounted on poly-l-lysine coated slides, which were prepared at least 30 min prior to mounting. At least 45 min after mounting, all sections in the primary antibody and omit primary antibody control groups were washed three times for $10 \mathrm{~min}$ each in phosphate-buffered saline (PBS) to remove formaldehyde, placed in methanol with $0.4 \% \mathrm{H}_{2} \mathrm{O}_{2}$ for 20 min to reduce endogenous peroxidase activity, and washed again three times in PBS for 10 mins each. Then, sections were treated with $1 \%$ sodium borohydride in $0.1 \mathrm{M}$ PB for 30 min to improve the staining, washed twice with $\mathrm{PB}$ two times for 5 min each, and washed with PBS for $30 \mathrm{~min}$.

For the initial D1 staining protocol, sections were treated with $1 \%$ goat serum and 0.3 Triton X-100 in PBS three times for 30 min each. Then, they were incubated with the primary antibody, anti-D1DR, (1:200) and the fab fragment (1:100) for two days at $4^{\circ} \mathrm{C}$ in $0.5 \%$ Triton X-100 in PBS. The primary antibody and fab fragment were preincubated for 60 min before treating sections to avoid cross-reactivity between the rat tissue and the primary antibody. After two days, the sections were removed and washed three times in PBS for 10 min each. They were 
placed in the secondary antibody for 60 min in $0.5 \%$ Triton X-100 in PBS followed by three PBS washes for $10 \mathrm{~min}$ each.

For the second D1 staining protocol, sections were treated with $1 \%$ normal goat serum, 0.5\% Triton X-100 in PBS for 60 min; $0.8 \%$ bovine serum albumin in PBS for 40 min; and incubated overnight at $4^{\circ} \mathrm{C}$ with the anti D1 antibody (1:500) in PBS with $0.5 \%$ Triton X-100. The next day, sections were rinsed in PBS three times for 10 min each and treated with biotinylated goat anti-rabbit secondary antibody (Vector Elite ABC kit) in PBS for 60 min. Then, the sections were washed with PBS three times for 10 min each and treated with an $\mathrm{ABC}$ peroxidase complex solution (Vector Elite ABC kit) for 60 min followed by another three PBS washes for $10 \mathrm{~min}$ each.

For DARPP-32 staining, sections were treated with $1 \%$ normal goat serum and $0.2 \%$ Triton X-100 in PBS for $30 \mathrm{~min}$; and incubated overnight at $4{ }^{\circ} \mathrm{C}$ with the anti-DARPP-32 primary antibody (1:3000), 0.5\% Triton-X, and PBS. The next day, sections were rinsed in PBS three times for 10 min each and treated with biotinylated goat anti-rabbit secondary antibody in PBS for $30 \mathrm{~min}$. Then, the sections were washed with PBS three times for $10 \mathrm{~min}$ each and treated with an $\mathrm{ABC}$ peroxidase complex solution (Vector Elite $\mathrm{ABC}$ kit) for $30 \mathrm{~min}$ followed by another three PBS washes for 10 min each.

After the last step in each protocol, the sections were treated with $0.0005 \% 3,30$ diaminobenzidine (DAB) and $0.0001 \mathrm{H}_{2} \mathrm{O}_{2}$ in PBS for 2-4 min to create the insoluble brown chromogen. The sections were washed with PBS three times for $10 \mathrm{~min}$ each and let to dry overnight. After going through a series of ethanol and xylene washes, the slides were coverslipped with DPX (Electron Microscopy Sciences, Hatfield, PA, USA). 
Cresyl violet-staining tissues were washed in PBS and 0.1M PB for 10 min each and left to dry overnight. After going through a series of ethanol and xylene washes, they were stained with $0.1 \%$ cresyl violet solution and coverslipped with DPX.

\section{Statistical Analyses}

The analyzed sections were NAcc, Layer V of PRh, and subregions CA1, CA3, and DG of HPC. Sections were chosen using the cresyl violet-stained samples for each subject. Examples of each subregion can be seen in Figure 1. The antibody and omit sections were examined using standard light microscopy (Leica Microsystems MZ9.5 and DMRBE microscopes, Buffalo Grove, IL, USA). The photomicrographs were taken using a CCD camera (Leica Microsystems DFC300FX) and the Image-Pro Express MC program (MediaCybernetics, Silver Spring, MD, USA) on a Windows PC. Magnification used during these analyses was 200X for NAcc and Layer V of PRh, and 400X for HPC subregions.

The differences between antibody and omit control groups were measured by determining the measure of luminance, the intensity of light emitted from a tissue, as performed in Butler et al., (2019). Darker staining leads to lower luminance values and lighter staining leads to higher luminance values. Then, the difference between the luminance values of antibodystained sections and omits was calculated to find specific staining for each subject. In comparison, a lower difference value between omit and antibody staining would mean less specific staining. These values were compared through an independent samples t-test comparing METH and saccharin groups. 


\section{Figure 1}

Cresyl Violet Staining
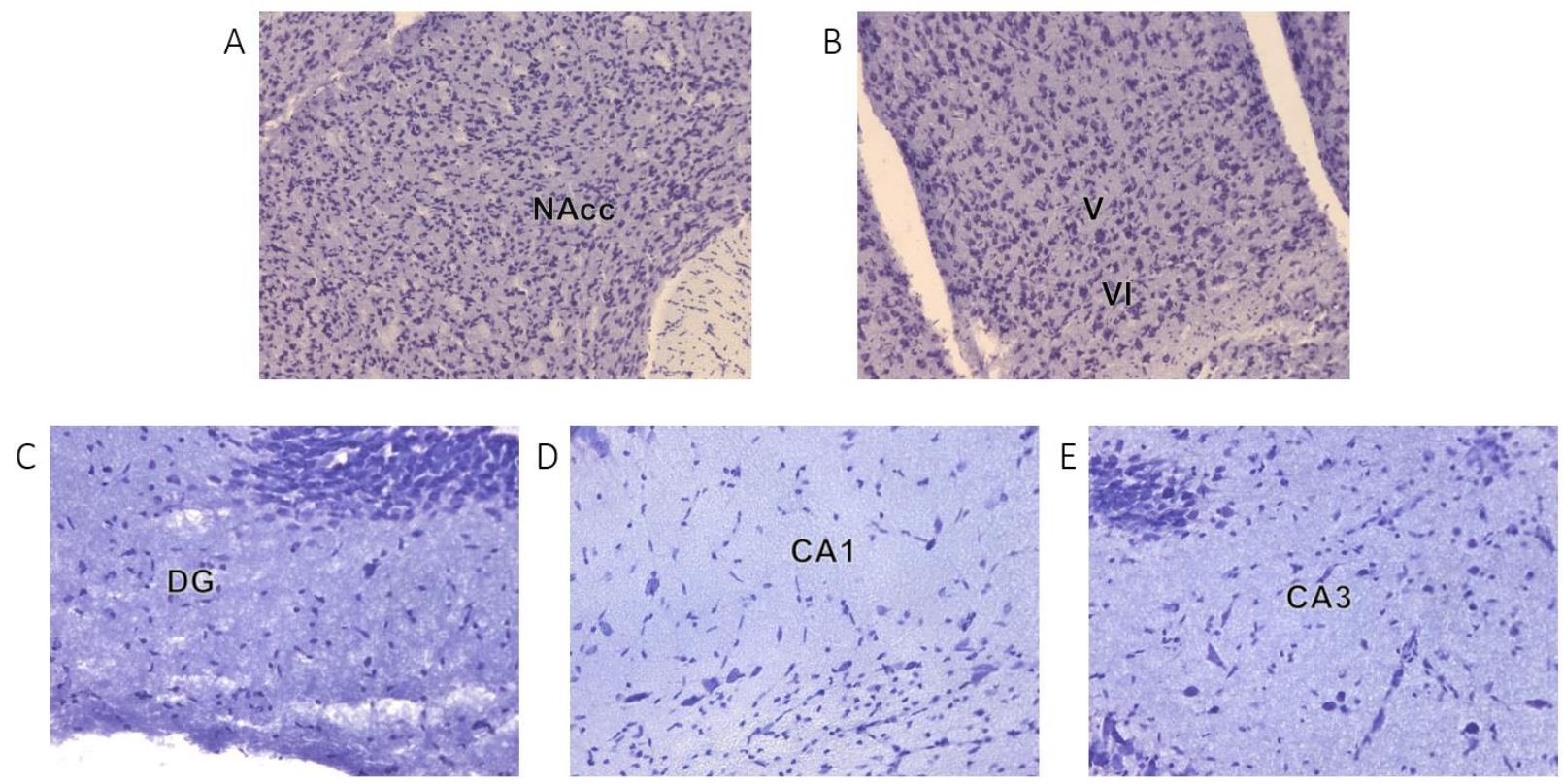

Note. (A) Nucleus accumbens core. Magnification 100X. (B) Layer V and VI of perirhinal cortex. Magnification 100X. (C) Dentate gyrus of hippocampus. Magnification 200X. (D) CA1 of hippocampus. Magnification 200X. (E) CA3 of hippocampus. Magnification 200X. 


\section{CHAPTER III: RESULTS}

\section{Dopamine D1 Histology}

The initial D1 staining protocol resulted in high background staining in both primary antibody and omit primary antibody control groups. The high level of non-specific staining could not be reduced by several modifications to the procedure. The second D1 antibody staining protocol, using the ABC method, was successful (Figure 2). There is a noticeable difference between primary antibody and control groups, indicating the presence of specific D1 staining. Unfortunately, there were not enough tissues to be processed to analyze the treatment effects.

\section{Figure 2}

D1 Staining in NAcc

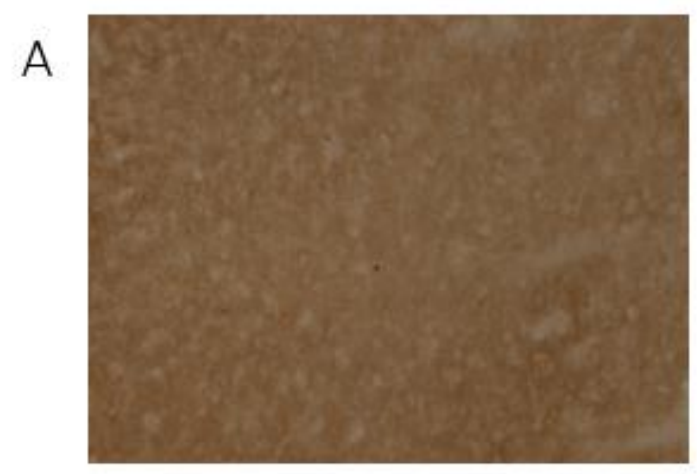

B

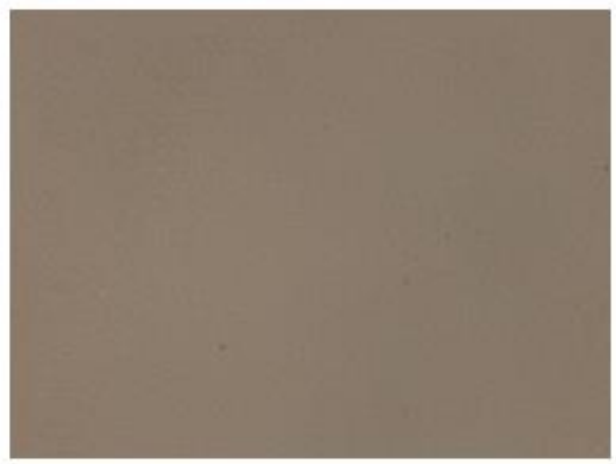

Note. (A) Antibody staining; luminance value of 1573. Magnification 200X. (B) Omit; luminance value of 1999. Magnification 200X.

\section{DARPP-32 Histology}

\section{Nucleus Accumbens}

The DARPP-32 staining protocol resulted in visibly different primary antibody and omit primary antibody control staining (See Figure 3). Specific luminance values were calculated by 
taking the difference between values for antibody and control sections of each subject. Mean specific luminance values of NAcc tissues for METH and saccharin groups were compared through an independent samples t-test. The values of METH and saccharin groups were similar (See Table 2). There was no significant effect of condition on the specific luminance values of NAcc, $t(3)=-1.76, p=.177$. Antibody staining for each subject of the NAcc group can be found in Appendix A.

\section{Figure 3}

DARPP-32 Staining in the NAcc
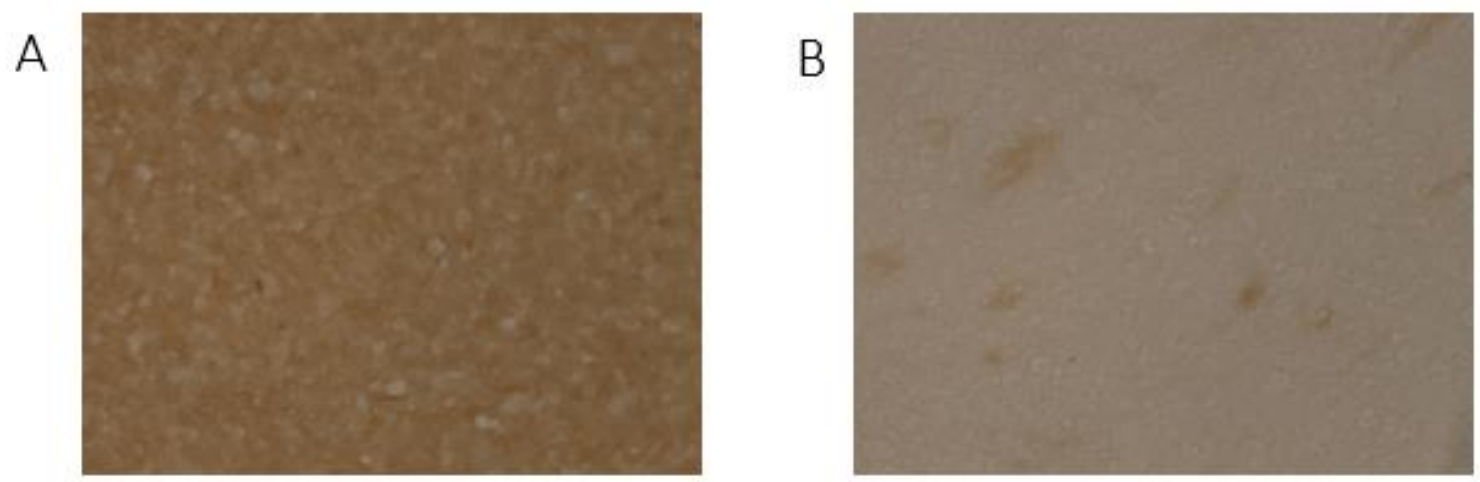

Note. METH group; adult-onset. (A) Antibody staining; luminance value of 1704. Magnification 200X. (B) Omit; luminance value of 2011. Magnification 200X. 


\section{Table 2}

Mean Specific Luminance Values for METH and Saccharin Groups in Each Subregion.

\begin{tabular}{|c|c|c|c|c|}
\hline & & & & \\
\hline & \multicolumn{2}{|c|}{ METH } & \multicolumn{2}{|c|}{ Saccharin } \\
\hline & $M$ & $S D$ & $M$ & $S D$ \\
\hline NAcc & 345.52 & 54.01 & 407.47 & 27.86 \\
\hline $\mathrm{PRh}$ & 238.03 & 176.65 & 295.86 & 80.72 \\
\hline DG & 131.81 & 52.72 & 221.31 & 123.89 \\
\hline CA1 & 120.42 & 43.53 & 217.23 & 109.68 \\
\hline CA3 & 74.82 & 47.06 & 203.32 & 114.73 \\
\hline
\end{tabular}

\section{Perirhinal Cortex}

The DARPP-32 staining protocol resulted in visibly different antibody and omit staining (See Figure 4). Mean specific luminance values of PRh tissues for METH and saccharin groups were compared through an independent samples t-test. The values of METH and saccharin groups were similar (See Table 2). There was no significant effect of condition on the specific luminance values of PRh, $t(3)=-0.52, p=.638$. Antibody staining for each subject of the PRh group can be found in Appendix B. 


\section{Figure 4}

DARPP-32 Staining in the PRh
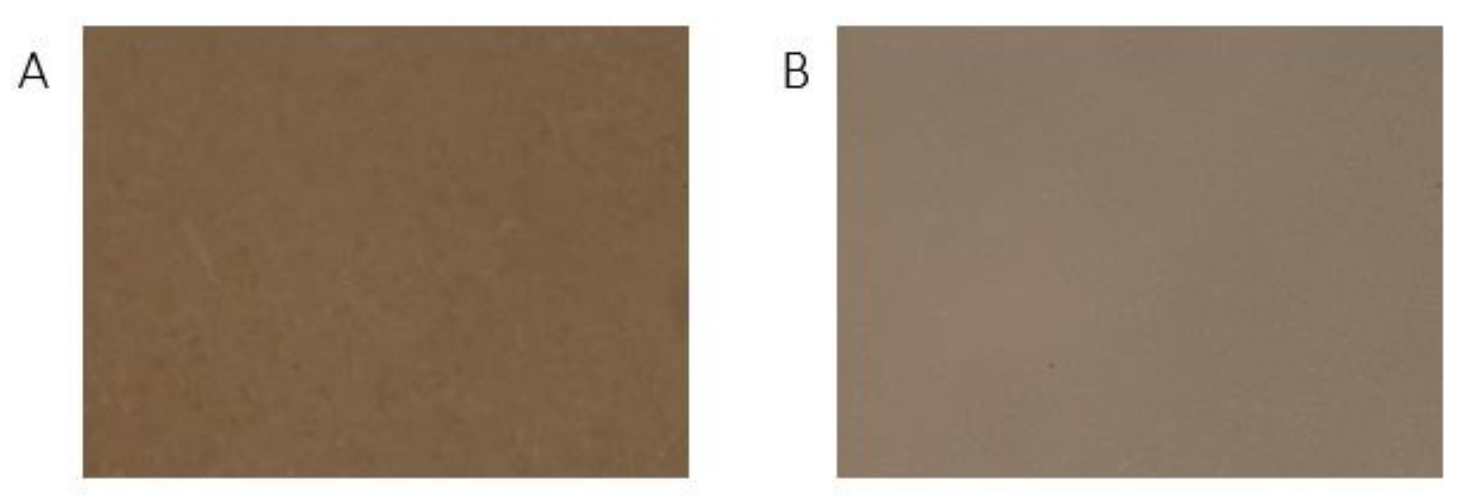

Note. METH group; adolescent-onset. (A) Antibody staining; luminance value of 1623.

Magnification 200X. (B) Omit; luminance value of 1968. Magnification 200X.

\section{Hippocampus}

The DARPP-32 staining protocol resulted in visibly different antibody and omit staining (See Figure 5). Mean specific luminance values of HPC subregions for METH and saccharin groups were compared through independent samples t-tests. The values of METH and saccharin groups were similar in each subregion (See Table 2). There was no significant effect of condition on the specific luminance values of DG, $t(4)=-1.15, p=.314, \mathrm{CA} 1, t(4)=-1.42, p=.228$, or CA3, $t(4)=-1.79, p=.147$. Antibody staining for each subject of the HPC subregions can be found in Appendix C. 


\section{Figure 5}

DARPP-32 Staining in the HPC

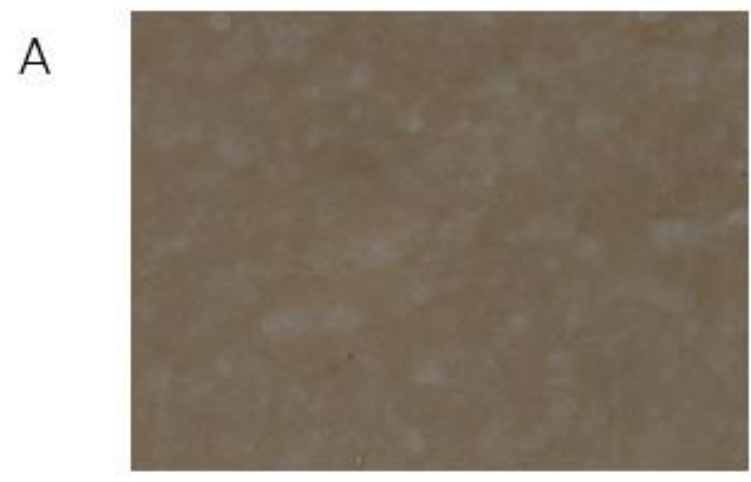

B

Note. METH group; adult-onset. (A) Antibody staining in CA1; luminance value of 1688.

Magnification 400X. (B) Omit staining in CA1; luminance value of 1846. Magnification 400X.

Because there were not any differences between METH and saccharin groups, I examined the effect of age-of-onset on DARPP-32 expression for HPC subjects. In DG, specific luminance values for the adult-onset group $(M=159.6, S D=30.38)$ were comparable to the adolescent-onset group $(M=185.04, S D=124.48)$. These values were not significantly different, $t(4)=-0.27, p=.801$. In CA1, specific luminance values for the adult-onset group $(M=144.26$, $S D=19.5)$ were comparable to the adolescent-onset group $(M=181.11, S D=115.06)$. These values were not significantly different, $t(4)=-0.42, p=.693$. In CA3, specific luminance values for the adult-onset group $(M=95.41, S D=43.42)$ were comparable to the adolescent-onset group $(M=160.9, S D=126.39)$. These values were not significantly different, $t(4)=-0.68, p=$ .535 . 


\section{CHAPTER IV: DISCUSSION}

Repeated administration of METH has been shown to influence levels of D1 receptors (e.g., McCabe et al., 1987) and DARPP-32 (e.g., Chen \& Chen, 2005) expression in the rat brain. Previous experiments that used D1 receptor (Ares-Santos et al., 2012) and DARPP-32 (Zachariou et al., 2006) knock-out mice illustrated that both D1 and DARPP-32 might be required for the action effects of drugs. Because most studies in the past targeted only the striatum, this experiment was designed to investigate the chronic effects of METH on D1 receptor and DARPP-32 expression levels in NAcc, PRh, and HPC. However, the results of D1 staining were inconclusive, and the hypothesis on DARPP-32 was not supported. The results showed that there were no differences between DARPP-32 staining of METH and saccharin subjects, which implies that METH did not have a chronic effect on DARPP-32 expression.

The first procedure used for D1 staining was unsuccessful and resulted in similarly stained antibody and omit control groups. To troubleshoot this issue, I decreased the primary antibody concentration to 1:250,1:500,1:1000, and 1:2000; however, the results did not change. This could be because the antibodies selected were rat primary antibodies, which is often complicated by high background staining. Although I used a Fab fragment to block endogenous immunoglobulins by incubating it with the primary antibodies, it is possible that this method is not as effective as indirect staining with an antibody raised in another animal in reducing nonspecific binding. Following this procedure, I also tried blocking the tissues with Fab fragment prior to incubating with the primary antibody as advised by the seller; however, this method did not yield to any promising results either. The second D1 primary antibody coupled with the $\mathrm{ABC}$ method resulted in better results. The antibody-stained tissues were visibly darker than omit tissues. However, because of time restrictions and limited resources, I was unable to stain 
enough tissues for this project. Future studies may benefit from selecting the latter procedure when staining for D1 receptors in rat brain.

To answer the second research question, I examined the effects of METH selfadministration on each brain region. Although the mean specific luminance values for METH groups were lower, which means that they had lower levels of staining, there were no significant differences between conditions for any of the subregions. These findings may not support the previous research that illustrated significant chronic DARPP-32 alteration in rat striatum (e.g., Chen \& Chen, 2005), but they align with the results of Westbrook et al. (2020), in which the analyses showed no difference on D1 receptor expression levels in either PFC or NAc between METH and saccharin groups. Because DARPP-32 is co-localized with D1 receptors, one might expect DARPP-32 levels to be unaffected when the number of D1 receptors are not altered.

The conflicting results between previous research and the current experiment could also be because of differences in methodology. While Westbrook et al. (2020) utilized selfadministration of METH and saccharin, most previous studies used experimenter-delivered injections of METH and saline. It is possible that self-administration of saccharin, which was at a comparable rate to METH self-administration, might be similarly rewarding. For instance, Hajnal et al. (2004) found that sucrose intake increases DA levels in NAc. In addition, it has been illustrated that saccharin can suppress the rewarding properties of cocaine after a long-term cocaine treatment (Lenoir et al., 2007). Also, in animal models of food addiction, saccharin intake has been found to be increased via opioid agonists (Zhang \& Kellyer, 2002) and decreased via opioid antagonists (MacDonald et al., 2003). Similarly, Chien et al. (2012) found that pretreatment with opioid antagonists can attenuate METH-induced locomotor activity as well as 
DARPP-32 phosphorylation. Overall, the similarities between the rewarding properties of drugs and sweet-tasting substances may have influenced our results.

Visual examination of the HPC of each subject illustrate an apparent difference in the DARPP-32 staining between adult-onset subjects in the METH group compared to adult-onset subjects in the saccharin group, while the difference between the adolescent-onset groups is less noticeable. However, because of the small sample size, I was unable to examine the potential relationship between the age-of-onset and drug condition. It is possible that chronic METH administration could have different effects with different age-of-onset exposures. Ultimately, there were no overall differences between adult-onset and adolescent-onset groups on the specific staining values.

Along with the small sample size, the current experiment had other important limitations. Brain tissues used in this experiment were originally dissected to be analyzed with methods other than immunohistochemistry. Typically, in an anatomical research project, brains from subjects would be processed as whole-brain sections. Because I used dissected brain regions rather than whole brains, it was not possible to section and mount them all comparably. Also, because the dissected brain regions provided no structural information of the exact location, I was unable to determine while analyzing the PRh pieces whether the selected tissues were from the same dorsal and ventral coordinates. Although the PRh analyses focused on Layer V, it is possible that the selected sections could have been cut from very different coordinates of the region. Similarly, when selecting HPC pieces, I was unable to use tissues from the same exact coordinates due to technical issues such as tissues being lost while being processed or having random tears and artifacts. Lastly, the luminance value analysis used in this experiment intended to measure specific staining by comparing antibody and omit tissues. The difference between antibody and 
omit tissue values represented the intensity of DARPP-32 expression. It is possible that if the tissues were examined through cell counting, the results could differ. However, the luminance value analysis used in this experiment might be a more reliable procedure considering that visualization and quantifying of stained cells would be more difficult and potentially biased. Using luminance values rather than cell counting allows to account for all DARPP-32 specific staining even if cells with DARPP-32 immunoreactivity may not be clearly visible.

The questions such as whether METH had a chronic effect on D1 and DARPP-32 expression and whether there is a relationship between age-of-onset and drug-induced long-term changes remain to be clarified. Future studies could implement a similar design with a larger sample size and potentially with a more neutral control substance for self-administration. The differences between the effects of self-administration and experimenter-administration should also be thoroughly examined. 


\section{REFERENCES}

Anglin, M. D., Burke, C., Perrochet, B., Stamper, E., \& Dawud-Noursi, S. (2000). History of the methamphetamine problem. Journal of Psychoactive Drugs, 32(2), 137-141. https://doi.org/10.1080/02791072.2000.10400221

Ares-Santos, S., Granado, N., \& Moratalla, R. (2013). The role of dopamine receptors in the neurotoxicity of methamphetamine. Journal of Internal Medicine, 273(5), 437-453. https://doi.org/10.1111/joim.12049

Bardo, M. T., Valone, J. M., \& Bevins, R. A. (1999). Locomotion and conditioned place preference produced by acute intravenous amphetamine: role of dopamine receptors and individual differences in amphetamine self-administration. Psychopharmacology, 143(1), 39-46. https://doi.org/10.1007/s002130050917

Berendse, H. W., Groenewegen, H. J., \& Lohman, A. H. (1992). Compartmental distribution of ventral striatal neurons projecting to the mesencephalon in the rat. The Journal of Neuroscience, 12(6), 2079-2103. https://doi.org/10.1523/jneurosci.12-06-02079.1992

Berke, J. D., \& Hyman, S. E. (2000). Addiction, dopamine, and the molecular mechanisms of memory. Neuron, 25(3), 515-532. https://doi.org/10.1016/s0896-6273(00)81056-9

Bibb, J. A., Chen, J., Taylor, J. R., Svenningsson, P., Nishi, A., Snyder, G. L., ... Greengard, P. (2001). Effects of chronic exposure to cocaine are regulated by the neuronal protein Cdk5. Nature, 410(6826), 376-380. https://doi.org/10.1038/35066591

Blum, K., Werner, T., Carnes, S., Carnes, P., Bowirrat, A., Giordano, J., ... Gold, M. (2012). Sex, drugs, and rock 'n' roll: Hypothesizing common mesolimbic activation as a function of reward gene polymorphisms. Journal of Psychoactive Drugs, 44(1), 38-55. https://doi.org/10.1080/02791072.2012.662112 
Borgkvist, A., Usiello, A., Greengard, P., \& Fisone, G. (2007). Activation of the cAMP/PKA/DARPP-32 signaling pathway is required for morphine psychomotor stimulation but not for morphine reward. Neuropsychopharmacology, 32(9), 1995-2003. https://doi.org/10.1038/sj.npp.1301321

Brown, J. M., Riddle, E. L., Sandoval, V., Weston, R. K., Hanson, J. E., Crosby, M. J., ... Fleckenstein, A. E. (2002). A single methamphetamine administration rapidly decreases vesicular dopamine uptake. Journal of Pharmacology and Experimental Therapeutics, 302(2), 497-501. https://doi.org/10.1124/jpet.302.2.497

Brown, M. W., \& Aggleton, J. P. (2001). Recognition memory: What are the roles of the perirhinal cortex and hippocampus? Nature Reviews Neuroscience, 2(1), 51-61. https://doi.org/10.1038/35049064

Buck, J. M., \& Siegel, J. A. (2015). The effects of adolescent methamphetamine exposure. Frontiers in Neuroscience, 9. https://doi.org/10.3389/fnins.2015.00151

Bunney, B. S., \& Aghajanian, G. K. (1978). d-Amphetamine-induced depression of central dopamine neurons: Evidence for mediation by both autoreceptors and a striato-nigral feedback pathway. Naunyn-Schmiedeberg's Archives of Pharmacology, 304(3), 255-261. https://doi.org/10.1007/bf00507966

Butler, J. L., Barham, B. J., \&amp; Heidenreich, B. A. (2019). Comparison of indirect peroxidase and avidin-biotin-peroxidase complex (ABC) immunohistochemical staining procedures for c-fos in rat brain. Journal of Anatomy, 234(6), 936-942. https://doi.org/10.1111/joa.12967 
Cadet, J. L., Jayanthi, S., McCoy, M. T., Beauvais, G., \& Cai, N. S. (2010). Dopamine D1 receptors, regulation of gene expression in the brain, and neurodegeneration. CNS \& Neurological Disorders - Drug Targets, 9(5), 526-538.

https://doi.org/10.2174/187152710793361496

Cass, W. (1997). Decreases in Evoked Overflow of Dopamine in Rat Striatum after Neurotoxic Doses of Methamphetamine. The Journal of Pharmacology and Experimental Therapeutics, 280(1), 105-113. https://doi.org/0022-3565/97/2801-0105\$03.00/0

Chen, P.C., \& Chen, J.C. (2005). Enhanced cdk5 activity and p35 translocation in the ventral striatum of acute and chronic methamphetamine-treated rats. Neuropsychopharmacology, 30(3), 538-549. https://doi.org/10.1038/sj.npp.1300604

Chien, C.C., Lee, Y.J., Fan, L.W., Ho, I.K., \& Tien, L.T. (2012). Naloxonazine, a specific muopioid receptor antagonist, attenuates the increment of locomotor activity induced by acute methamphetamine in mice. Toxicology Letters, 212(1), 61-65. https://doi.org/10.1016/j.toxlet.2012.04.022

Courtney, K. E., \& Ray, L. A. (2014). Methamphetamine: An update on epidemiology, pharmacology, clinical phenomenology, and treatment literature. Drug and Alcohol Dependence, 143, 11-21. https://doi.org/10.1016/j.drugalcdep.2014.08.003

Deutch, A. Y., \& Cameron, D. S. (1992). Pharmacological characterization of dopamine systems in the nucleus accumbens core and shell. Neuroscience, 46(1), 49-56. https://doi.org/10.1016/0306-4522(92)90007-o

Fienberg, A. A., Hirol, N., Mermelstein, P. G., Song, J., Snyder, G. L., Nishi, A., ... Greengard, P. (1998). DARPP-32: Regulator of the Efficacy of Dopaminergic Neurotransmission. Science, 281(5378), 838-842. https://doi.org/10.1126/science.281.5378.838 
Fleckenstein, A. E., Metzger, R. R., Gibb, J. W., \& Hanson, G. R. (1997). A rapid and reversible change in dopamine transporters induced by methamphetamine. European Journal of Pharmacology, 323(2-3). https://doi.org/10.1016/s0014-2999(97)00148-9

Giros, B., Jaber, M., Jones, S. R., Wightman, R. M., \& Caron, M. G. (1996). Hyperlocomotion and indifference to cocaine and amphetamine in mice lacking the dopamine transporter. Nature, 379(6566), 606-612. https://doi.org/10.1038/379606a0

Gonzales, R., Ang, A., McCann, M. J., \& Rawson, R. A. (2008). An emerging problem: Methamphetamine abuse among treatment seeking youth. Substance Abuse, 29(2), 7180. https://doi.org/10.1080/08897070802093312

Gonzales, R., Mooney, L., \& Rawson, R. A. (2010). The methamphetamine problem in the United States. Annual Review of Public Health, 31(1), 385-398. https://doi.org/10.1146/annurev.publhealth.012809.103600

Greengard, P. (2001). The neurobiology of slow synaptic transmission. Science, 294(5544), 1024-1030. https://doi.org/10.1126/science.294.5544.1024

Gross, N. B., Duncker, P. C., \& Marshall, J. F. (2011). Striatal dopamine D1 and D2 receptors: Widespread influences on methamphetamine-induced dopamine and serotonin neurotoxicity. Synapse, 65(11), 1144-1155. https://doi.org/10.1002/syn.20952

Haber, S. N. (2014). The place of dopamine in the cortico-basal ganglia circuit. Neuroscience, 282, 248-257. https://doi.org/10.1016/j.neuroscience.2014.10.008

Hajnal, A., Smith, G. P., \& Norgren, R. (2004). Oral sucrose stimulation increases accumbens dopamine in the rat. American Journal of Physiology-Regulatory, Integrative and Comparative Physiology, 286(1). https://doi.org/10.1152/ajpregu.00282.2003 
Johnson, S. W., \& North, R. A. (1992). Opioids excite dopamine neurons by hyperpolarization of local interneurons. The Journal of Neuroscience, 12(2), 483-488. https://doi.org/10.1523/jneurosci.12-02-00483.1992

Johnston, L., Miech, R., O'Malley, P., Bachman, J., Schulenberg, J., \& Patrick, M. (2019). Monitoring the Future national survey results on drug use, 1975-2018: Overview, key findings on adolescent drug use. https://doi.org/10.3998/2027.42/150621

Jones, C. M., Compton, W. M., \&amp; Mustaquim, D. (2020). Patterns and characteristics of methamphetamine use among adults - United States, 2015-2018. MMWR. Morbidity and Mortality Weekly Report, 69(12), 317-323. https://doi.org/10.15585/mmwr.mm6912a1

Kang, S., Paul, K., Hankosky, E. R., Cox, C. L., \& Gulley, J. M. (2016a). D1 receptor-mediated inhibition of medial prefrontal cortex neurons is disrupted in adult rats exposed to amphetamine in adolescence. Neuroscience, 324, 40-49. https://doi.org/10.1016/j.neuroscience.2016.02.064

Kang, S., Wu, M. M., Galvez, R., \& Gulley, J. M. (2016b). Timing of amphetamine exposure in relation to puberty onset determines its effects on anhedonia, exploratory behavior, and dopamine D1 receptor expression in young adulthood. Neuroscience, 339, 72-84. https://doi.org/10.1016/j.neuroscience.2016.09.044

Kealy, J., \& Commins, S. (2011). The rat perirhinal cortex: A review of anatomy, physiology, plasticity, and function. Progress in Neurobiology, 93(4), 522-548. https://doi.org/10.1016/j.pneurobio.2011.03.002 
Kleven, M. S., Perry, B. D., Woolvertom, W. L., \& Seiden, L. S. (1990). Effects of repeated injections of cocaine on D1 and D2 dopamine receptors in rat brain. Brain Research, 532(1-2), 265-270. https://doi.org/10.1016/0006-8993(90)91768-c

Koob, G. F. (1992). Drugs of abuse: anatomy, pharmacology and function of reward pathways. Trends in Pharmacological Sciences, 13, 177-184. https://doi.org/10.1016/01656147(92)90060-j

Kutlu, M. G., \& Gould, T. J. (2016). Effects of drugs of abuse on hippocampal plasticity and hippocampus-dependent learning and memory: contributions to development and maintenance of addiction. Learning \& Memory, 23(10), 515-533. https://doi.org/10.1101/lm.042192.116

Langley, K. C., Bergson, C., Greengard, P., \& Ouimet, C. C. (1997). Co-localization of the D1 dopamine receptor in a subset of DARPP-32-containing neurons in rat caudate-putamen. Neuroscience, 78(4), 977-983. https://doi.org/10.1016/s0306-4522(96)00583-0

Lenoir, M., Serre, F., Cantin, L., \&amp; Ahmed, S. H. (2007). Intense Sweetness Surpasses Cocaine Reward. PLoS ONE, 2(8). https://doi.org/10.1371/journal.pone.0000698

Lin, X.-H., Hashimoto, T., Kitamura, N., Murakami, N., Shirakawa, O., \& Maeda, K. (2002). Decreased calcineurin and increased phosphothreonine-DARPP-32 in the striatum of rats behaviorally sensitized to methamphetamine. Synapse, 44(3), 181-187. https://doi.org/10.1002/syn.10071

Lupica, C. R., Riegel, A. C., \& Hoffman, A. F. (2004). Marijuana and cannabinoid regulation of brain reward circuits. British Journal of Pharmacology, 143(2), 227-234. https://doi.org/10.1038/sj.bjp.0705931 
MacDonald, A. F., Billington, C. J., \& Levine, A. S. (2003). Effects of the opioid antagonist naltrexone on feeding induced by DAMGO in the ventral tegmental area and in the nucleus accumbens shell region in the rat. American Journal of Physiology-Regulatory, Integrative and Comparative Physiology, 285(5). https://doi.org/10.1152/ajpregu.00271.2003

McCabe, R. T., Hanson, G. R., Dawson, T. M., Wamsley, J. K., \& Gibb, J. W. (1987). Methamphetamine-induced reduction in D1 and D2 dopamine receptors as evidenced by autoradiography: Comparison with tyrosine hydroxylase activity. Neuroscience, 23(1), 253-261. https://doi.org/10.1016/0306-4522(87)90287-9

McCaffrey, B. R. (1995). Pulse check. National trends in drug abuse. Abt Associates.

Miller, C. A., \& Marshall, J. F. (2005). Molecular substrates for retrieval and reconsolidation of cocaine-associated contextual memory. Neuron, 47(6), 873-884. https://doi.org/10.1016/j.neuron.2005.08.006

Nairn, A. C., Svenningsson, P., Nishi, A., Fisone, G., Girault, J.-A., \& Greengard, P. (2004). The role of DARPP-32 in the actions of drugs of abuse. Neuropharmacology, 47, 14-23. https://doi.org/10.1016/j.neuropharm.2004.05.010

Nishi, A., Bibb, J. A., Matsuyama, S., Hamada, M., Higashi, H., Nairn, A. C., \& Greengard, P. (2002). Regulation of DARPP-32 dephosphorylation at PKA- and Cdk5-sites by NMDA and AMPA receptors: distinct roles of calcineurin and protein phosphatase-2A. Journal of Neurochemistry, 81(4), 832-841. https://doi.org/10.1046/j.1471-4159.2002.00876.x 
O'Dell, S. J., Weihmuller, F. B., \& Marshall, J. F. (1993). Methamphetamine-induced dopamine overflow and injury to striatal dopamine terminals: Attenuation by dopamine D1or D2 Antagonists. Journal of Neurochemistry, 60(5), 1792-1799. https://doi.org/10.1111/j.1471-4159.1993.tb13405.x

Ouimet, C. C., Miller, P. E., Hemmings, H. C., Walaas, S. I., \& Greengard, P. (1984). DARPP32, a dopamine- and adenosine 3':5'-monophosphate-regulated phosphoprotein enriched in dopamine-innervated brain regions. III. Immunocytochemical localization. The Journal of Neuroscience, 4(1), 111-124. https://doi.org/10.1523/jneurosci.04-0100111.1984

Rajput, P. S., Kharmate, G., Somvanshi, R. K., \& Kumar, U. (2009). Colocalization of dopamine receptor subtypes with dopamine and cAMP-regulated phosphoprotein (DARPP-32) in rat brain. Neuroscience Research, 65(1), 53-63. https://doi.org/10.1016/j.neures.2009.05.005

Rawson, R. A., Gonzales, R., \& Brethen, P. (2002). Treatment of methamphetamine use disorders: an update. Journal of Substance Abuse Treatment, 23(2), 145-150. https://doi.org/10.1016/s0740-5472(02)00256-8

Rawson, R. A., Gonzales, R., Obert, J. L., McCann, M. J., \& Brethen, P. (2005). Methamphetamine use among treatment-seeking adolescents in Southern California: Participant characteristics and treatment response. Journal of Substance Abuse Treatment, 29(2), 67-74. https://doi.org/10.1016/j.jsat.2005.04.001 
Reichel, C. M., Schwendt, M., McGinty, J. F., Olive, M. F., \& See, R. E. (2010). Loss of object recognition memory produced by extended access to methamphetamine selfadministration is reversed by positive allosteric modulation of metabotropic glutamate receptor 5. Neuropsychopharmacology, 36(4), 782-792. https://doi.org/10.1038/npp.2010.212

Ritz, M., Lamb, R., Goldberg, \& Kuhar, M. (1987). Cocaine receptors on dopamine transporters are related to self-administration of cocaine. Science, 237(4819), 1219-1223. https://doi.org/10.1126/science.2820058

Robinson, T. E., \& Becker, J. B. (1982). Behavioral sensitization is accompanied by an enhancement in amphetamine-stimulated dopamine release from striatal tissue in vitro. European Journal of Pharmacology, 85(2), 253-254. https://doi.org/10.1016/00142999(82)90478-2

Salgado, S., \& Kaplitt, M. G. (2015). The nucleus accumbens: A comprehensive review. Stereotactic and Functional Neurosurgery, 93(2), 75-93. https://doi.org/10.1159/000368279

Substance Abuse and Mental Health Services Administration (SAMHSA). (2014). The DAWN Report: Emergency Department Visits Involving Methamphetamine: 2007 to 2011. Rockville, MD.

Schröder, N., O'Dell, S. J., \& Marshall, J. F. (2003). Neurotoxic methamphetamine regimen severely impairs recognition memory in rats. Synapse, 49(2), 89-96. https://doi.org/10.1002/syn.10210 
Scofield, M. D., Heinsbroek, J. A., Gipson, C. D., Kupchik, Y. M., Spencer, S., Smith, A. C., ... Kalivas, P. W. (2016). The nucleus accumbens: Mechanisms of addiction across drug classes reflect the importance of glutamate homeostasis. Pharmacological Reviews, 68(3), 816-871. https://doi.org/10.1124/pr.116.012484

Scott, J. C., Woods, S. P., Matt, G. E., Meyer, R. A., Heaton, R. K., Atkinson, J. H., \& Grant, I. (2007). Neurocognitive effects of methamphetamine: A critical review and meta-analysis. Neuropsychology Review, 17(3), 275-297. https://doi.org/10.1007/s11065-007-9031-0

Smith, A. R., Garris, P. A., \& Casto, J. M. (2015). Real-time monitoring of electrically evoked catecholamine signals in the songbird striatum using in vivo fast-scan cyclic voltammetry. Journal of Chemical Neuroanatomy, 66-67, 28-39. https://doi.org/10.1016/j.jchemneu.2015.04.002

Spear, L. P. (2000). The adolescent brain and age-related behavioral manifestations. Neuroscience \& Biobehavioral Reviews, 24(4), 417-463. https://doi.org/10.1016/s01497634(00)00014-2

Stojanovic, T., Orlova, M., Sialana, F. J., Höger, H., Stuchlik, S., Milenkovic, I., ... Lubec, G. (2017). Validation of dopamine receptor DRD1 and DRD2 antibodies using receptor deficient mice. Amino Acids, 49(6), 1101-1109. https://doi.org/10.1007/s00726-0172408-3

Stephans, S. E., \& Yamamoto, B. K. (1994). Methamphetamine-induced neurotoxicity: Roles for glutamate and dopamine efflux. Synapse, 17(3), 203-209. https://doi.org/10.1002/syn.890170310 
Stott, S. R. W., \& Ang, S. L. (2013). The generation of midbrain dopaminergic neurons. In Patterning and Cell Type Specification in the Developing CNS and PNS: Comprehensive (Vol. 1, pp. 435-453). essay, Academic Press.

Svenningsson, P., Nishi, A., Fisone, G., Girault, J.-A., Nairn, A. C., \& Greengard, P. (2004). DARPP-32: An integrator of neurotransmission. Annual Review of Pharmacology and Toxicology, 44(1), 269-296. https://doi.org/10.1146/annurev.pharmtox.44.101802.121415

Walaas, S. I., Aswad, D. W., \& Greengard, P. (1983). A dopamine- and cyclic AMP-regulated phosphoprotein enriched in dopamine-innervated brain regions. Nature, 301(5895), 6971. https://doi.org/10.1038/301069a0

Wermuth, L. (2000). Methamphetamine use: Hazards and social influences. Journal of Drug Education, 30(4), 423-433. https://doi.org/10.2190/gmh7-3fwx-1ac1-rwxp

Westbrook, S. R., Dwyer, M. R., Cortes, L. R., \& Gulley, J. M. (2020). Extended access selfadministration of methamphetamine is associated with age- and sex-dependent differences in drug taking behavior and recognition memory in rats. Behavioural Brain Research, 390, 112659. https://doi.org/10.1016/j.bbr.2020.112659

Yger, M., \& Girault, J.-A. (2011). DARPP-32, jack of all trades? Master of which? Frontiers in Behavioral Neuroscience, 5. https://doi.org/10.3389/fnbeh.2011.00056

Yokoyama, C., Okamura, H., \& Ibata, Y. (1995). Dopamine D2-like receptors labeled by [3H]YM-09151-2 in the rat hippocampus: characterization and autoradiographic distribution. Brain Research, 681(1-2), 153-159. https://doi.org/10.1016/00068993(95)00308-d 
Zachariou, V., Sgambato-Faure, V., Sasaki, T., Svenningsson, P., Berton, O., Fienberg, A. A., ... Nestler, E. J. (2005). Phosphorylation of DARPP-32 at threonine-34 is required for cocaine action. Neuropsychopharmacology, 31(3), 555-562. https://doi.org/10.1038/sj.npp.1300832

Zhang, M. \& Kelley, A. (2002). Intake of saccharin, salt, and ethanol solutions is increased by infusion of a mu opioid agonist into the nucleus accumbens. Psychopharmacology, 159(4), 415-423. https://doi.org/10.1007/s00213-001-0932-y 


\section{APPENDIX A: DARPP-32 ANTIBODY STAINING ON NUCLEUS ACCUMBENS}

SACC

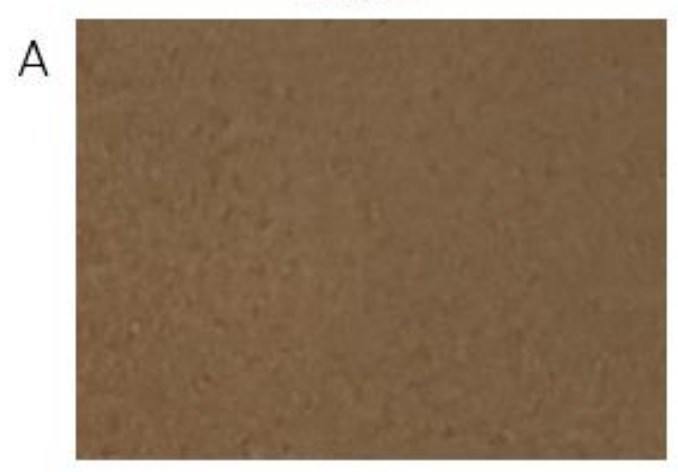

(A) Adolescent subject; 409

B

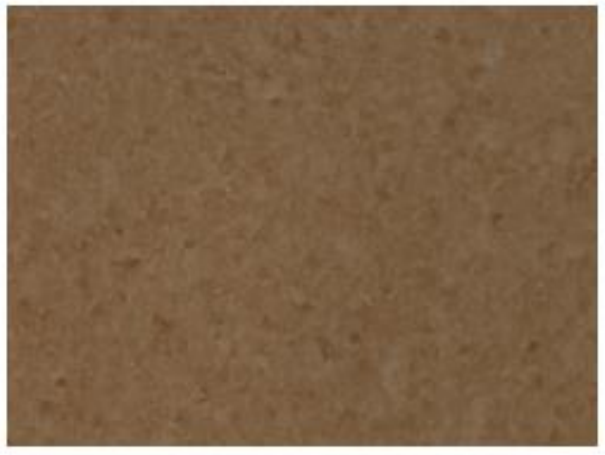

(B) Adolescent subject; 379

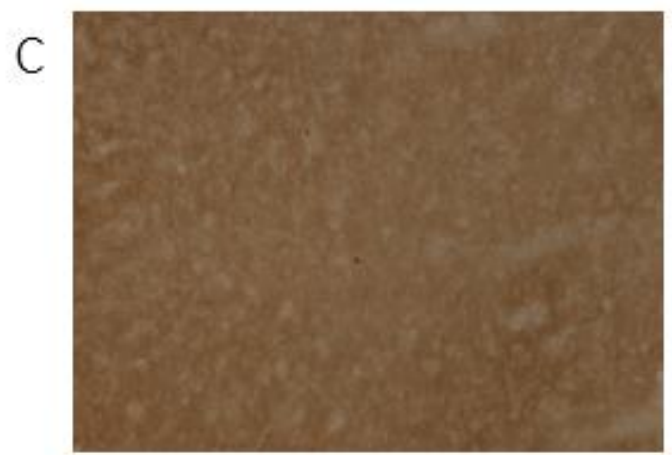

(C) Adolescent subject; 435
METH

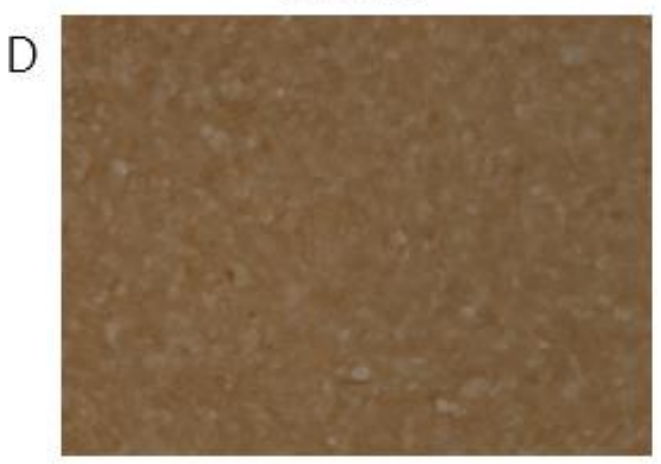

(D) Adult subject; 307

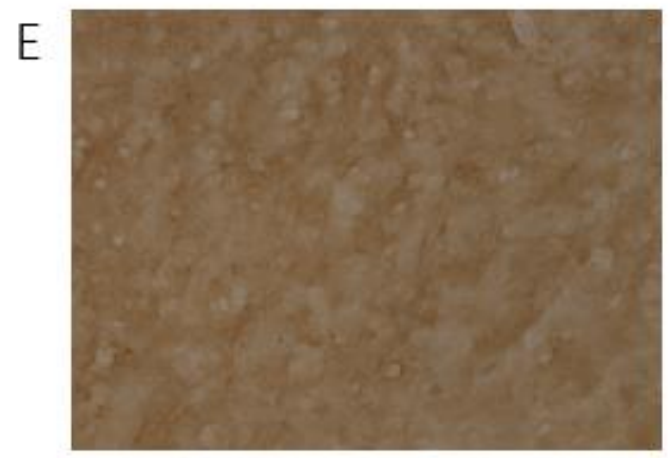

(E) Adult subject; 384

Note. The values represent individual luminance values for specific staining calculated by taking the difference between omit primary controls and primary antibody values. Magnification 200X. 


\section{APPENDIX B: DARPP-32 ANTIBODY STAINING ON PERIRHINAL CORTEX}

SACC

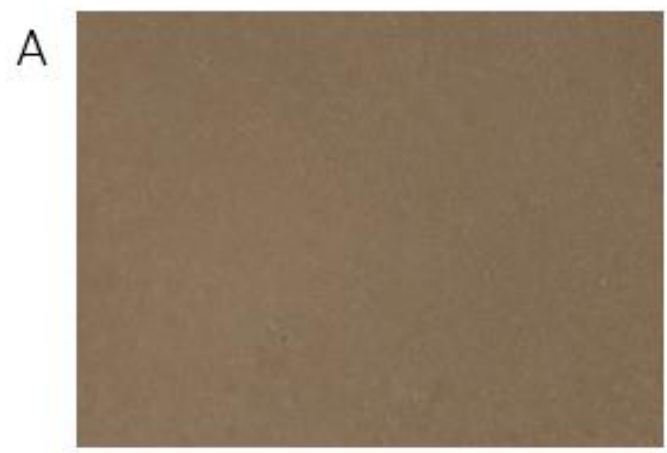

(A) Adolescent subject; 203

B

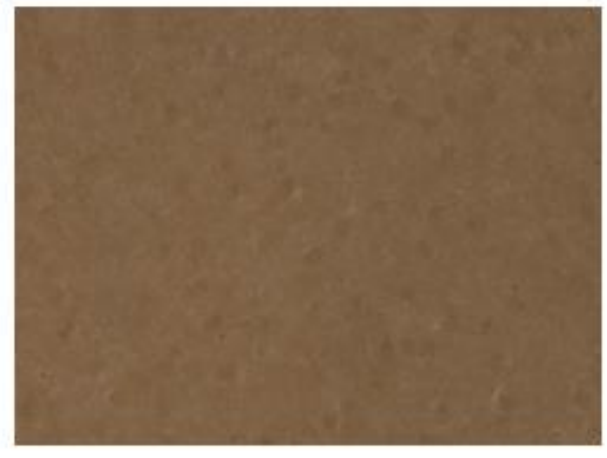

(B) Adolescent subject; 344

C

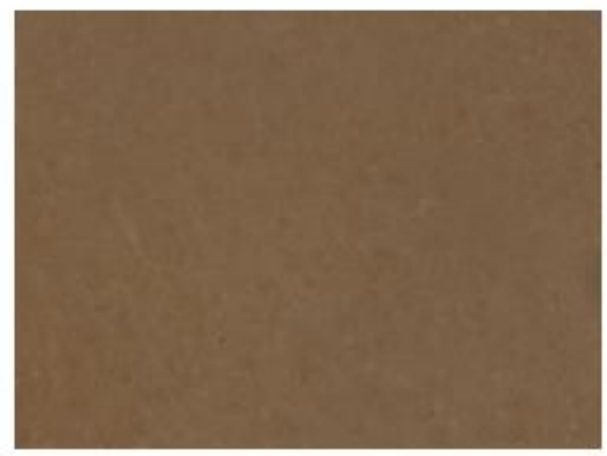

METH

D

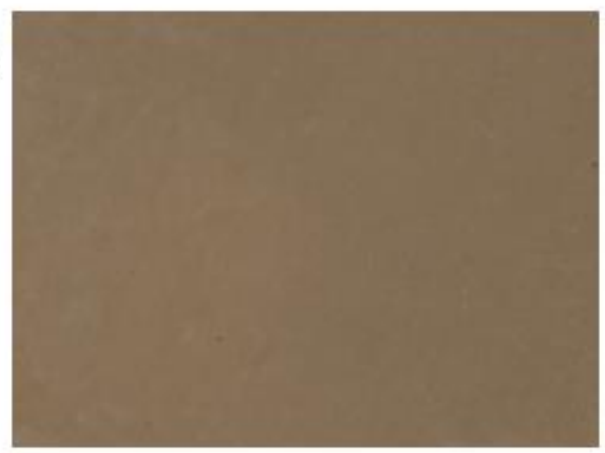

(D) Adult subject; 113

E

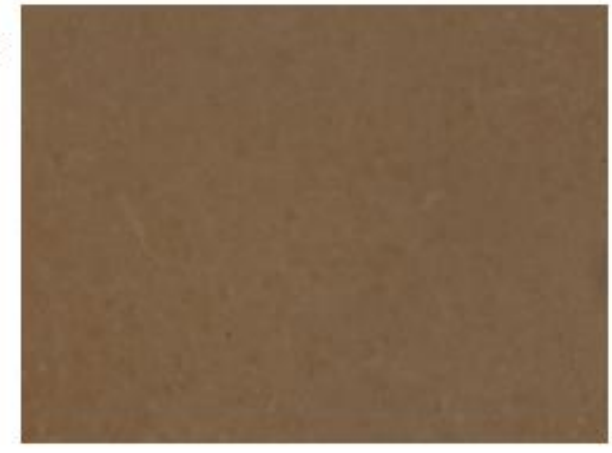

(E) Adolescent subject; 363

(C) Adult subject; 341

Note. The values represent individual luminance values for specific staining calculated by taking the difference between omit primary controls and primary antibody values. Magnification 200X. 


\section{APPENDIX C: DARPP-32 ANTIBODY STAINING ON HIPPOCAMPUS}

SACC

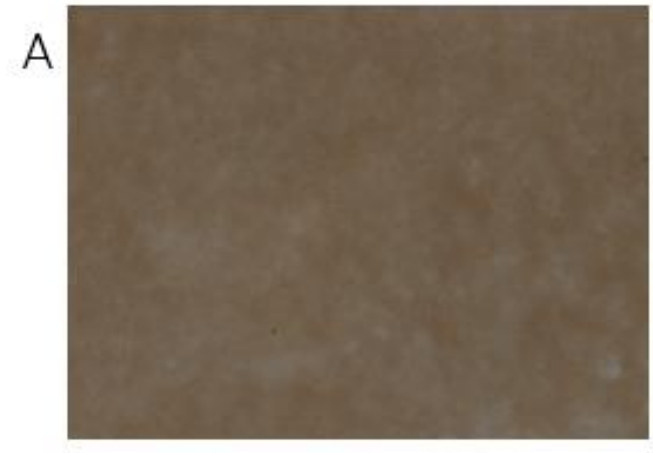

(A) Adult subject; 364

B

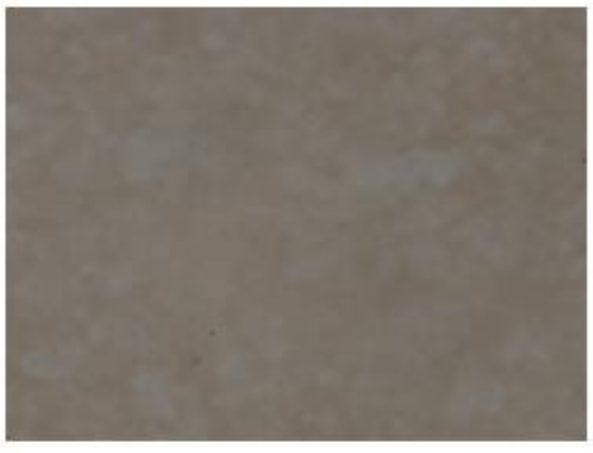

(B) Adolescent subject; 146

C

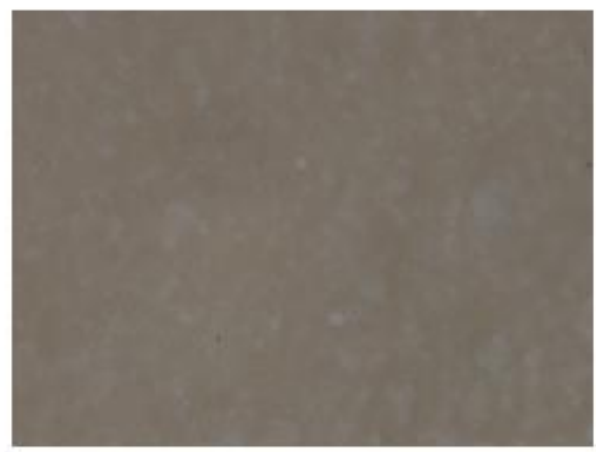

(C) Adolescent subject; 153
METH

D

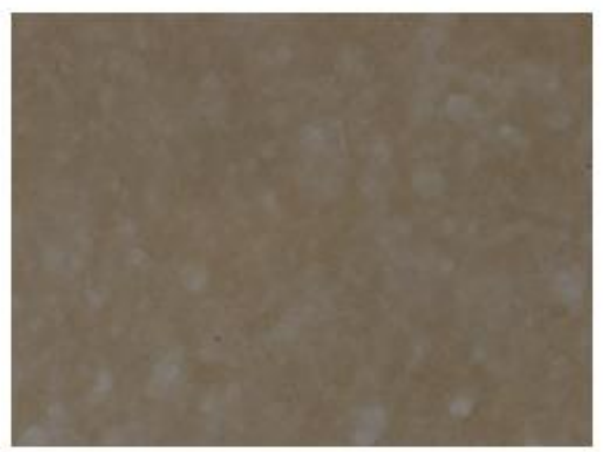

(D) Adult subject; 138

E

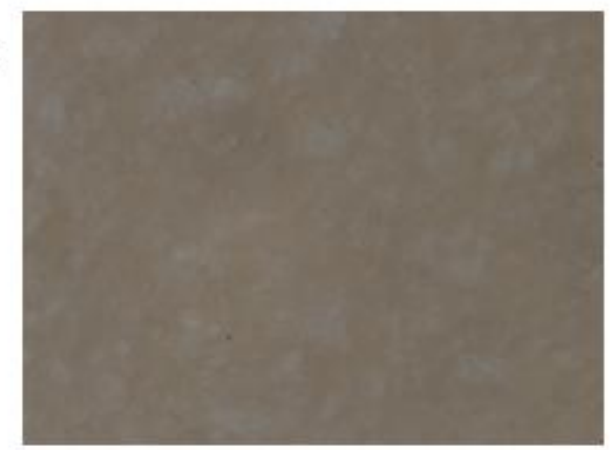

(E) Adult subject; 181

F

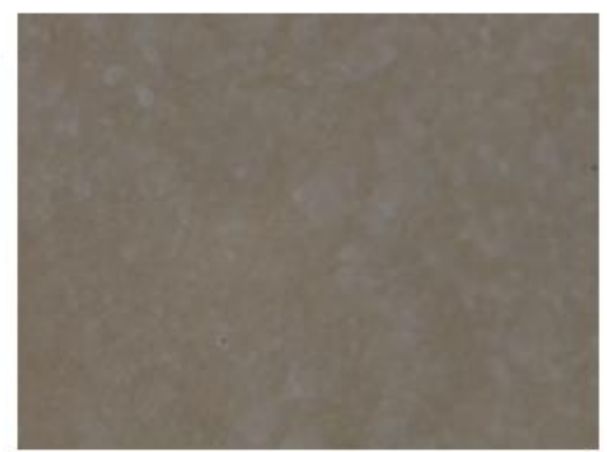

(F) Adolescent subject; 76

Note. DG Staining. The values represent individual luminance values for specific staining calculated by taking the difference between omit primary controls and primary antibody values. Magnification 400X. 
SACC

A

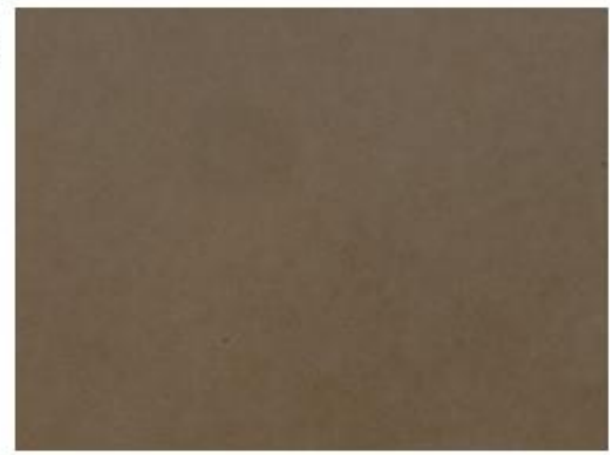

(A) Adult subject; 342

B

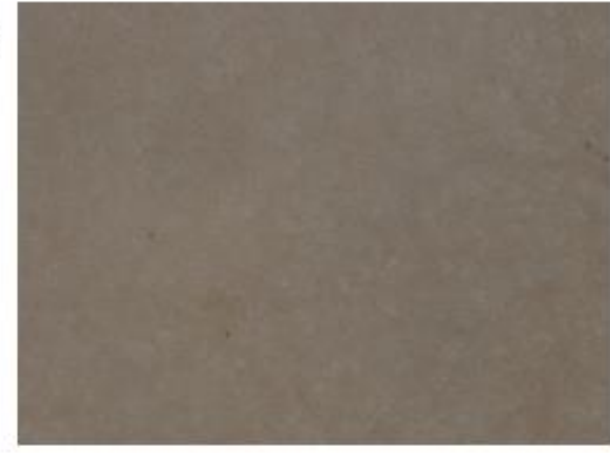

(B) Adolescent subject; 135

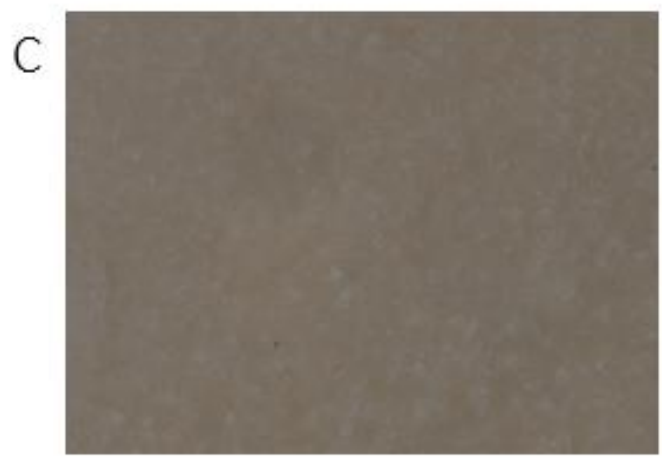

(C) Adolescent subject; 175
METH

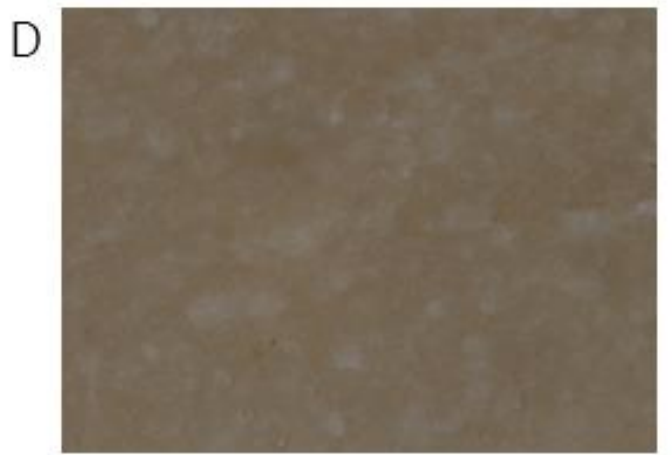

(D) Adult subject; 158

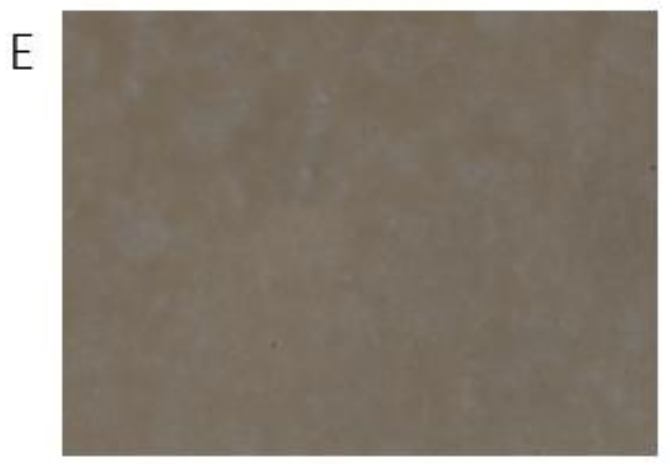

(E) Adult subject; 130

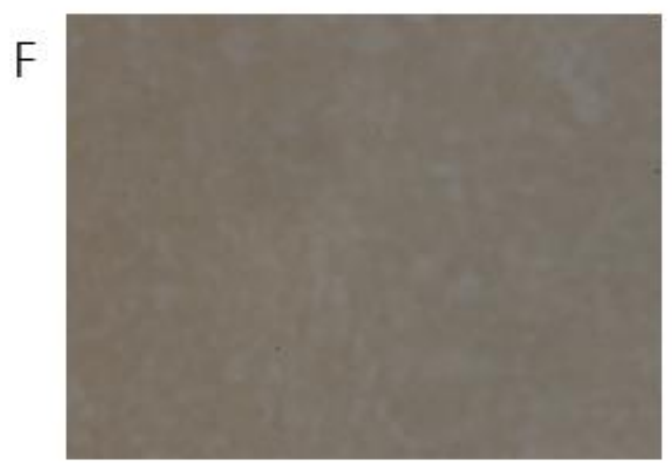

(F) Adolescent subject; 73

Note. CA1 Staining. The values represent individual luminance values for specific staining calculated by taking the difference between omit primary controls and primary antibody values. Magnification 400X. 
SACC

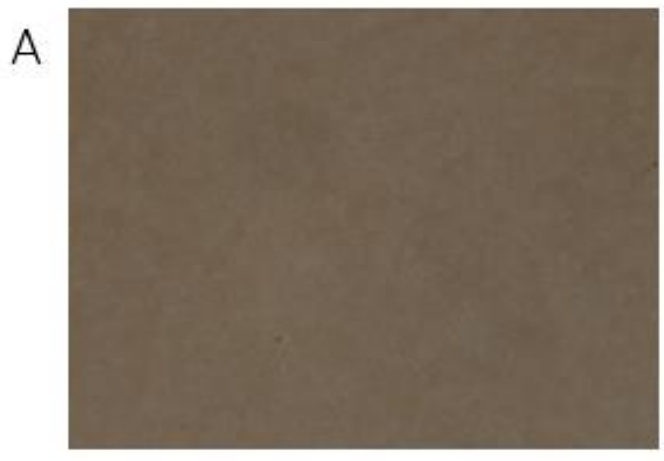

(A) Adult subject; 336

B

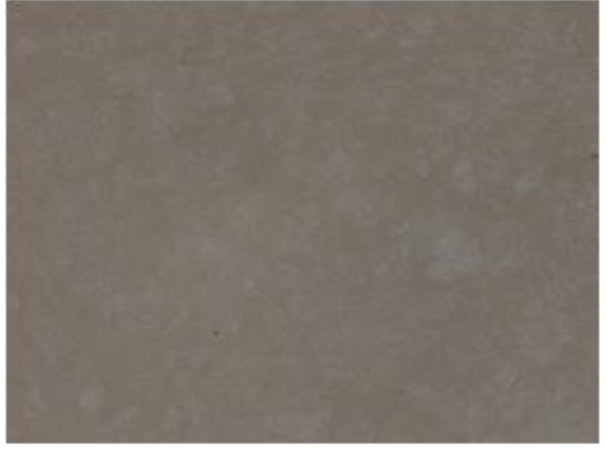

(B) Adolescent subject; 142

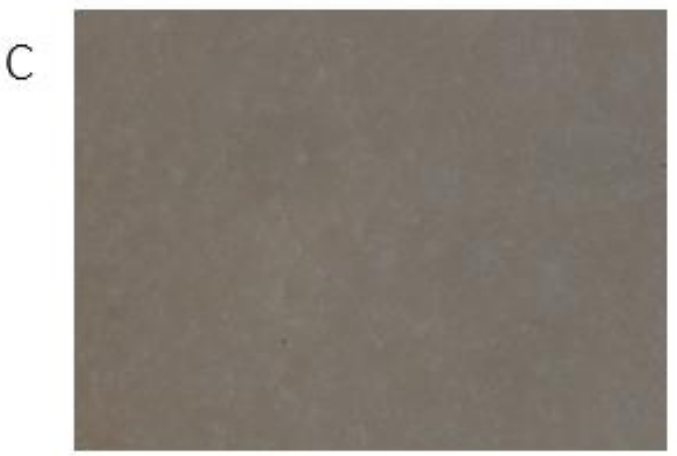

(C) Adolescent subject; 133
METH

D

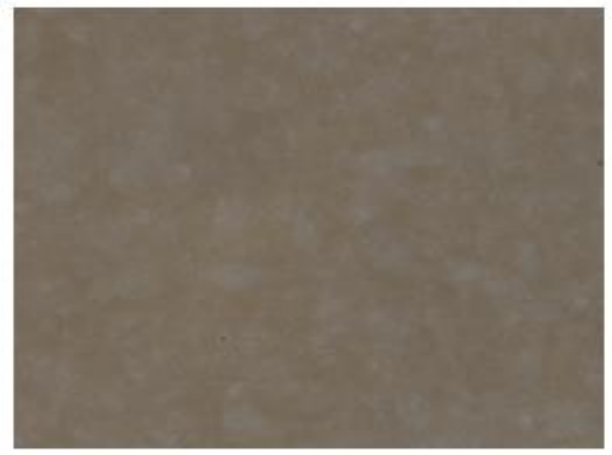

(D) Adult subject; 65

E

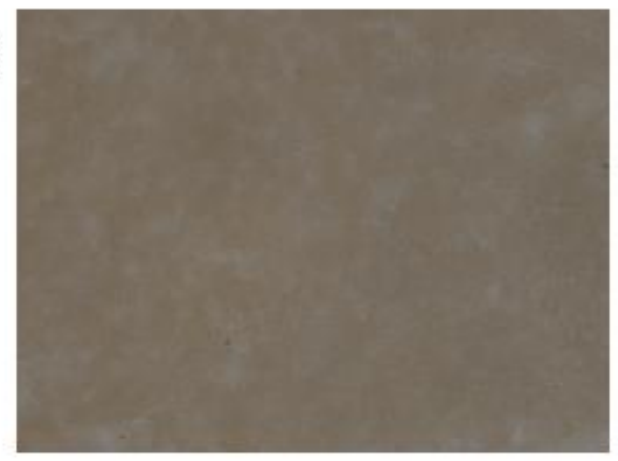

(E) Adult subject; 126

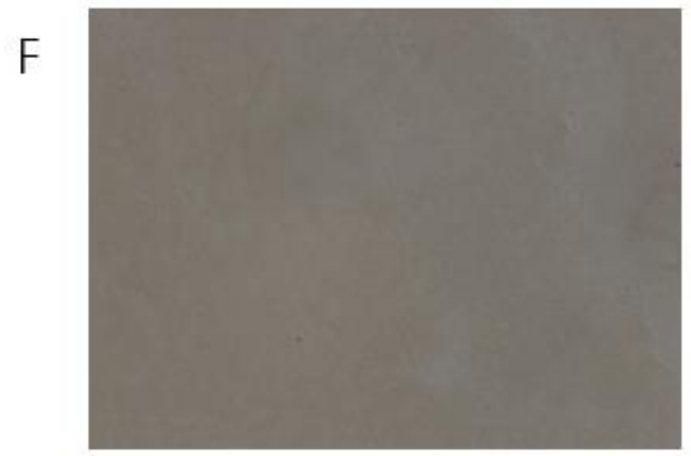

(F) Adolescent subject; 34

Note. CA3 Staining. The values represent individual luminance values for specific staining calculated by taking the difference between omit primary controls and primary antibody values. Magnification 400X. 